\title{
Mehmet Başbuğ Resimlerinde Hayvan İmgelerinin Göstergebilim Çözümlemesi
}

\author{
Rasim SOYLU ${ }^{1}$
}

$\ddot{\mathrm{Oz}}$

Mehmet Başbuğ çağdaş Türk resim sanatında adını ulusal ve uluslararası sanat platformlarında duyurmuş bir sanatçı olarak henüz çok erken bir zamanda aramızdan ayrılmıştır. Türk kültürü ve bilhassa Anadolu kültürü temalı resimleri Türk sanatında ulusal imgelerin kullanımında onu zirveye taşımıştır. Resimlerinde çoğunlukla İstiklal savaşı, Anadolu kadını, Türkistan teması, keçi ve at gibi imgeleri görmek mümkündür. Bu çalışmanın konusu ve amacı Mehmet Başbuğ'un resimlerinde yer alan hayvan imgelerinin göstergebilim analizlerinin yapılmasıdır. Göstergebilim göstergeleri inceleyen ve analiz eden bir bilim dalı olarak yirminci yüzyılda gelişmiştir. Kendinden başka bir şeyi gösteren olarak tanımlanan gösterge her yerde bulunduğu gibi sanat eseri üzerinde de yer alır. Aslında sanat eserinin kendisi de bir gösterge olarak ele alınabilir. Belirtiler, belirtkeler, ikonlar ve semboller sanat eseri üzerindeki en önemli göstergelerdir. Bir gösterge düz anlamı yanı sıra yan anlam ve derin anlam da ifade eder. Ayrıca bir gösterge karşıt anlamlarına da gönderme yapar. Göstergebilim göstergeleri inceleyen ve anlamlandıran bir bilim dalı olmakla birlikte, sanat eserlerini de incelemek ve çözümlemek için bir yöntem olarak kullanılmaktadır. Bu çalışmada Mehmet Başbuğ’un resimlerinde yer alan hayvan figürlerinden farklı on tanesi göstergebilim sanat eseri çözümleme yönteminden yararlanılarak çözümlenecektir. Göstergebilim sanat eseri incelemesinde Barthes ve Gremias tarafından geliştirilen göstergebilim çözümleme şemalarından anlam çözümleme şeması, karşıt anlamlar şeması, eyleyenler şeması ve göstergebilimsel dörtgen şeması üzerinde uygulamalı çözümlemeler yapılacaktır.

Anahtar Kelimeler: Göstergebilim, Mehmet Başbuğ, Türk Resim Sanatı, Hayvan İmgeleri

\section{Analysis of the Anımal Image in Mehmet Başbuğ Paintings with Semiotics}

\begin{abstract}
Mehmet Başbuğ passed away at a very early time as an artist who has made a name for himself in contemporary Turkish painting on national and international art platforms. His paintings with the theme of Turkish culture and especially Anatolian culture have brought him to the top in the use of national images in Turkish art. It is possible to see images such as the War of Independence, Anatolian cake, Turkestan theme, goat and horse in his paintings. The subject and purpose of this purpose is to make semiotics analysis of the animal images in Mehmet Başbuğ's paintings. Semiology developed in the twentieth century as a subject of study and analysis. It is located on the work of art as well as on the outside, showing something other than itself. The work of art itself can be considered as an indicator. Signs, symbols, and symbols are most important to the work of art. An indicator expresses its plain meaning as well as connotations and meanings. It also makes reference to the opposite meanings of a sign. Semiotics is being studied and used as a method to analyze and analyze works of art used as a science that makes sense. This market will be analyzed by using different semiotics art work analysis method on different animal figures in Mehmet Başbuğ's paintings. When the semiotic art work is examined, applied analysis will be made on high temperature analysis schemes, meaning analysis schemes, oppositional meanings schemes, actors diagrams and semiotic quadrilateral diagrams made by Barthes and Gremias.
\end{abstract}

Key Words: Semiotics, Mehmet Başbuğ, Turkish painting, Images of animal

Atıf İçin / Please Cite As:

Soylu, R. (2021). Mehmet Başbuğ resimlerinde hayvan imgelerinin göstergebilim çözümlemesi. Manas Sosyal Arassturmalar Dergisi, 10(4), 2226-2242.

Geliş Tarihi / Received Date: 04.02.2021

Kabul Tarihi / Accepted Date: 17.06.2021

\footnotetext{
${ }^{1}$ Doç. Dr. - Sakarya Üniversitesi Sanat Tasarım ve Mimarlık Fakültesi, rasimsoylu@hotmail.com

(D) ORCID: 0000-0001-7136-1928
} 


\section{Giriş}

Cumhuriyet döneminde öğretmen yetiştirmek amacıyla kurulan "Gazi Orta Muallim Mektebi ve Terbiye Enstitüsü" bugünkü adıyla Gazi Eğitim, Türk sanatına da pek çok değerli sanatçı ve sanat eğitimcisi yetiştirmiştir. Adnan Turani, Mustafa Ayaz, Turan Erol gibi Mehmet Başbuğ’da bu kurumdan yetişmiş bir sanatçı ve sanat eğitimcisidir. Yakın zamanda aramızdan ayrılan Başbuğ, eğitimciliği yanı sıra güçlü figüratif resimleriyle Türk sanat tarihinde şimdiden yerini almıştır. Resimlerinde daha çok Türk kültür imgeleri ve Anadolu temaları yer alan Başbuğ’un İstiklal savaşı konularında da çok çalışması vardır. Resimlerinde Anadolu ve Türk kültürünün güçlü imgeleri olarak bazı hayvan figürlerini özenerek tasvir etmiştir.

Ülkemizde olduğu gibi Türki devletlerde de tanınan ve etkinlikler yapan Başbuğ, bilhassa Kırgızistan Türkiye Manas Üniversitesi Güzel Sanatlar Fakültesi Resim Bölümü’nde sanat eğitimciliği ve Dekanlık yapmıştır. Türk kültürünü yakından inceleyen ve gözlemlerini büyük boyutlarda yaptı̆̆ resimlerle ölümsüzleştiren Başbuğ, Orta Asya Türkleri ile ortak kodları da yakından inceleme imkânı bulmuştur. Bunlar arasında önemli birer imge olarak hayvan figürlerini gösterge olarak ele almak ve düz anlamı yanı sıra yan anlamları ve derin anlamlarıyla çözümlemek bu araştırmanın ana konusunu teşkil eder. Ayrıca her göstergenin kendi anlamları yanı sıra karşıt anlamlarına da gönderme yapmasından yola çıkılarak karşıt anlamlar şeması da çözümlenecektir. Gremias'n eyleyenler şeması ve göstergebilimsel dörtgen şeması uygulaması da bu çalışmanın göstergebilim eser çözümleme yöntemleri içerisinde yer alacaktır.

\section{Göstergebilim ve Sanat Eseri Çözümleme Yöntemi}

Göstergebilim, göstergeleri inceleyen bir bilim dalı olarak 19. yüzyılın sonunda Fransız bilim adamı Saussure ve Amerikalı bilim adamı Peirce tarafindan temelleri atılııştır. Daha sonra 20. Yüzyılda Gremias, Barthes, Derrida, Eco gibi bilim adamları tarafindan geliştirilmiştir.

Gösterge kendisinden başka bir şeyi gösteren veya temsil eden şey olarak tarif edilir. Her türlü imge, iz, belirti, belirtke, işaret, simge, sembol, şifre, harf, yazı ses ve söz gösterge olarak tanımlanabilir (Rifat, 2013, s. 96). Trafik işaretleri, dilsiz alfabesi, dini, askeri ve ulusal semboller, tipik birer göstergedirler. Bir araç üzerindeki yağ, yakıt, hız, devir, hararet ve anıza göstergeleri tek anlamlı göstergelerdir. Ancak düz anlamı yanı sıra yan anlamları ve derin anlamları olan çok anlamlı göstergeler de vardır (Akerson, 2006, s. 17).

Günümüzde göstergebilim tıp biliminden sanat tarihine, edebiyattan kutsal kitap yorumlamalarına, moda ve reklam çözümlemelerinden sanat eleştirisine kadar pek çok alanda kullanılmaktadır. Saussure'e göre gösterge gösteren ve gösterilenden oluşur. Peirce'e göre ise gösteren ve gösterilenin yanı sıra yorumlayan faktörü de önemlidir. Ona göre eğer bir yorumlayan yoksa gösterge anlamını yitirir (A.g.e. s. 109-111). Bir sanat eseri göstergebilim yöntemi ile analiz edilebilir. Bu göstergebilim sanat eleştirisi olarak tanımlanabilir. Barthes, göstergebilim çözümlemelerinin sanat eleştirisinde yeni bir dönemin başladığına dikkati çeker (Uçan, 2003, s. 24-27).

Bir sanat eseri sanatçısının ruh haletini, üslubunu, ait olduğu dönemi, sanattaki yetkinliğini, yaratıcıllğını ve diğer sanatsal özelliklerini gösteren göstergeler içerebilir. Örneğin Van Gogh'un "Kargalar" resmi, firça izleri, kullandığı renkler, boyanın dokusu ve ilgilendiği imgeler onun ruhsal durumunu, sanatsal yetkinliğini, üslubunu ve ait olduğu dönemi çok güzel bir şekilde yansitır. Umberto Eco (1992, s. 18-34), sanat eserlerini açık yapıt olarak tanımlar. Ona göre her gösterge açık uçludur. Sanat eserini yapandan daha çok okuyan ve izleyen anlamlandırır. Sanat eserini yorumlayan her birey daha önce düşünülmemiş ihtimalleri sonsuz bir çeşitlilik içerisinde akla getirebilir.

20. yüzyılda göstergebilimin gelişmesine en çok katkı sağlayan bilim adamlarından Greimas'ın göstergebilimsel dörtgen şeması ve eyleyenler modeli, Chomsky derin yapı çözümlemesi, Hjelmslev'in anlatım-içerik düzlemi, Prop'un masal çözümlemek için geliştirdiği kahramanlar modeli ve Barthes'in göstergebilim çözümlemesi, göstergebilimin sanat eleştirisi için geliştirilmiş en iyi örneklerdir (Soylu, 2016, s. 41-44).

Ayrıca göstergebilim sanat eseri çözümleme çalışmalarında, düz anlam, yan anlam ve derin anlam çözümleme şeması, karşıt anlamlar şeması, eyleyenler şeması ve göstergebilimsel dörtgen şeması en çok kullanılan göstergebilim yöntemi olmuştur. 


\section{Sanatta Hayvan İmgesi}

Mağara döneminden itibaren insanların yaptıkları resimlerde hayvan imgeleri görülür. Mağara resimlerinde duvarlara çizilen resimlerde hayvanlar bazen av nesnesi bazen de korkulan birer tehlike imgesi olarak yer alırlar. Bu resimler ister taklit veya öykünme ister büyü veya idol olsunlar hayvan imgesinin sanatta her zaman önemli bir yerinin olduğunun göstergesidir.

Hayvan imgeleri, sanat tarihinin farklı dönemlerinde farklı sanat dalları içerisinde yapılan sanat eserlerinde sanatçılar tarafindan kullanılmaktadırlar. Varlık, canlı, doğa ilişkisi olarak, idol, ikon ve sembolik öğe olarak, dostluk, arkadaşlık, sadakat göstergesi olarak sanatçıların eserlerinde tasvir edilirler (Keten, 2018, s. 288).

Antik Mısır, Mezepotamya ve Anadolu Uygarlıklarında hayvan imgesinin kutsallık ve tapınma amaçlı sanatta yer aldığı görülür. Özellikle burçların hayvan imgeleriyle tasvir edilmesi en eski hayvan kültü örnekleridir. Orta Asya'dan itibaren Türk sanatında hayvan imgesinin 12 hayvanlı Türk takviminde, Türeyiş ve Ergenekon gibi Türk destanlarında açıkça görülür.

Rönesans'tan itibaren resim sanatının her döneminde ve akımında hayvan imgelerinin kullanıldığı görülür. Empresyonizm ile birlikte doğaya açılan sanatçılar hayvan figürlerini de eserlerine aktarmayı ihmal etmezler. Modern sanat içerisinde de hayvan figürleri soyutlanarak veya stilize edilerek yer almaya devam eder. Türk resim sanatı içerisinde hayvan imgesini pek çok sanatçının eserinde görmek mümkündür. Mehmet Başbuğ bilhassa at tasvirleriyle çağdaş Türk resim sanatında hayvan imgesini en çok yansıtan sanatçılardan birisidir.

\section{Mehmet Başbuğ}

1956 Yllında Diyarbakır' da doğan Mehmet Başbuğ, sanat eğitimini, Gazi Üniversitesi, Gazi Eğitim Fakültesi Resim Bölümü'nde lisans, mastır, sanatta yeterlilik ve doktora olarak tamamlar. 1976-1986 yillan arasında, Millî Eğitim Bakanlığı'na bağlı okullarda görev yapar.

1986-1994 y1llan arasında Gazi Üniversitesi Gazi Eğitim Fakültesi Resim Bölümü'nde Öğretim görevlisi olur. 1994-1999 yıllan arasında Süleyman Demirel Üniversitesi Güzel Sanatlar Fakültesi'nin kuruluş çalışmasında görev alarak Dekan yardımcllığ ve Resim Bölümü Başkanllğı yapar. Yurt içinde ve yurt dışında yüzlerce kişisel ve karma resim sergilerinde yer alır. Sanat yarışmalarında 17 ödüle sahiptir.

Ankara Ressamlar Birliği kurucu üyeliği, İstanbul Ressamlar Derneği üyeliği ve GESAM, Türkiye Güzel Sanat Eseri Sahipleri Meslek Birliği kurucu üyesi ve yönetim kurulu üyesi olmuştur. Kuveyt, Kazakistan, Kırgizistan, Türkmenistan, Özbekistan, Azerbaycan, Tataristan, Makedonya'da sanatsal ve incelemeler yapar. 1997 yllında 6 aylık süre ile Tataristan'daki okullarda görev alarak dersler verir. İdil-Ural Bölgesi Türk sanatları hakkında araştırma ve incelemelerde bulunur. 2008 y1lında doçent unvanı alan Başbuğ, 2009 yılından vefatına kadar Kırgızistan Türkiye Manas Üniversitesi, Güzel Sanatlar Fakültesi Dekanlık görevini yürütür (Başbuğ, 2016, s. 9).

Mehmet Başbuğ'un resimlerinde, Türk kültürü ve Anadolu insanının yaşamı, toplumsal gerçekçi bir üslupla ele alınmış ve bir tutku halini almıştır (Güngör, 2018, s.127). Sanatçı son döneminde savaş ve zafer konulu konularına yönelerek, Türk milleti için kutsal olan bayrak ve vatan gibi imgeleri resimlerinde yansıtmıştır. Kahramanlık ve milli duyguları içeren at imgesi resimlerinde kullandığı diğer hayvan imgeleri gibi Türk kültürü açısından önemli bir gösterge olarak kabul edilebilir

Yurt içi ve yurt dışında sayısız sergiler açan ve çizdiği çok sayıdaki at desenleri "Bozkırdaki Atlar" adıyla yayınlanan sanatçı Mehmet Başbuğ 7 Temmuz 2017 tarihinde Kırgızistan'ın Bişkek şehrinde hayata veda etmiştir. 


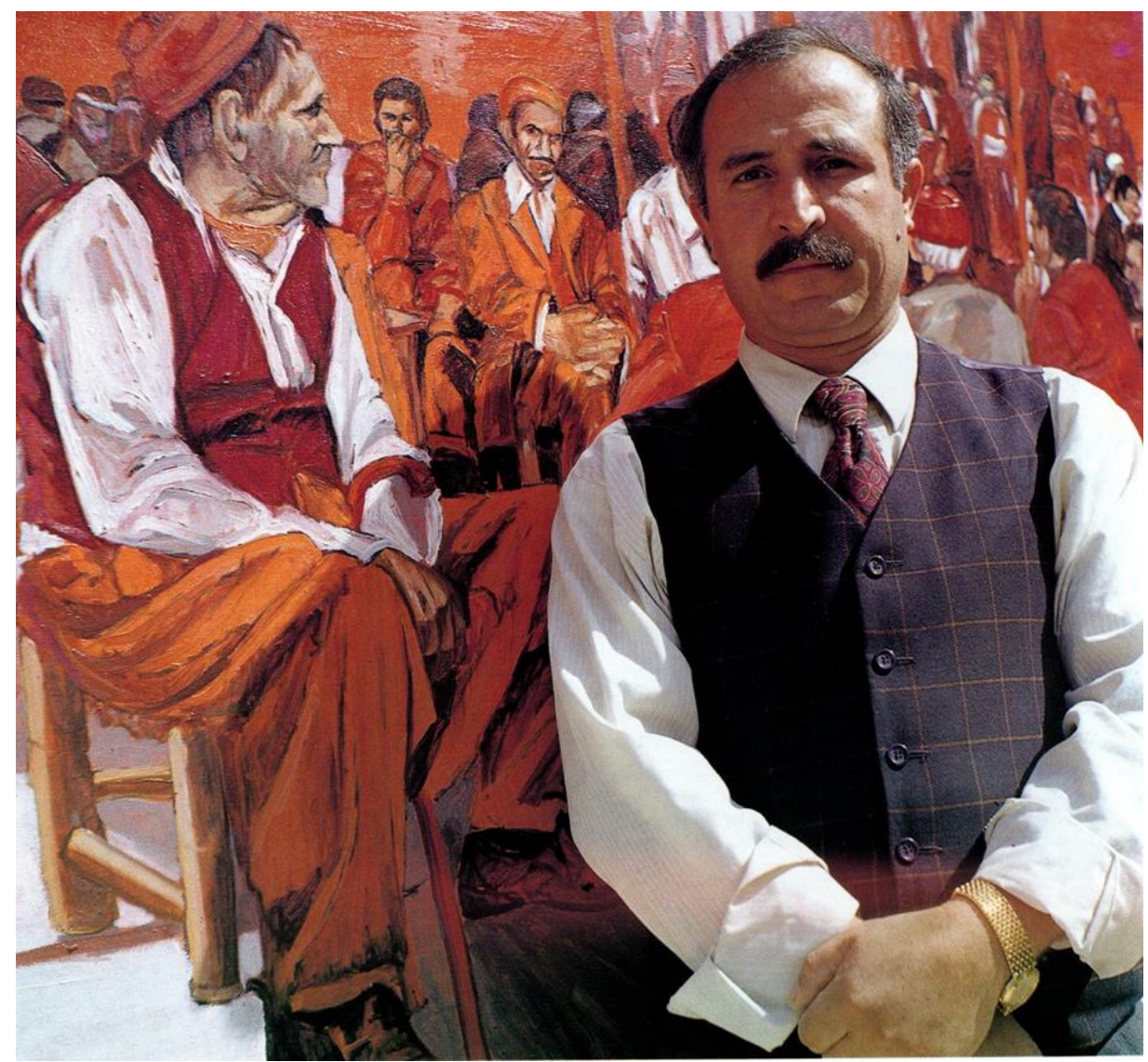

Görsel 1. Mebmet Başbŭg (Sergi Katoloğu, 2000, s. 2).

\section{Mehmet Başbuğ'un Sanat Anlayış1}

Ne yazık ki hayatının en verimli çağında aramızdan ayrılan Mehmet Başbuğ çağdaş Türk resim sanatında hem ürettiği resimleriyle hem de eğitimci kimliğiyle damgasını vurmuş önemli bir sanat şahsiyettir. Onun resimlerinde çoğunlukla Anadolu ve Orta Asya Türk kültürüne ait imgeleri görmek mümkündür. Seyfi Başkan (1991, s. 126), Mehmet Başbuğ’un resimlerinde genellikle Anadolu insanının hayat ilişkilerini ele alır. Onun tuvalinde sohbet eden insanlar, pazarcı kadınlar hemen her yerde karşılaşllabilecek görüntüler olduğunu söyler. O disiplinli bir desen ve renklendirme yeteneğine sahiptir.

Alaybey Karaoğlu'na göre (2000, s. 3) Mehmet Başbuğ çağının ve toplumun kendisinden beklediği sorumlulukların bilincinde olan ve kendisini toplumdan soyutlamayan bir sanatçıdır. Onun açık yürekli buram buram Anadolu kokan resimleri doğa ve köy figürlerini tuvalinde yansıtır. "Anadolu kırsal yaşamını ve bu yaşamın ayrılmaz bir parçası olan insanı, gündelik yaşamı içinde yöresel tiplemeleriyle kendine özgü bir atmosfer içinde ele alan Mehmet Başbuğ, eserlerinde Türk insanı ve yaşamı üzerine kurulmuş geniş bir dünya yaratmıştır. Sanatçı Anadolu insanın yanında Türk Dünyası'nın diğer toplum yaşantılarını da gelenek görenek ve efsaneleriyle eserlerine yansıtmış, Türk savaşları ve tarihini anlatan önemli yapıtlar ortaya koymuştur" (Aytekin, 2006, s. 20-23).

Tuba Güngör'e göre $(2020,1618)$ yaşamını sanata adayan Mehmet Başbuğ’un resimleri dört ana konuda toplanabilir. Bunlar Anadolu Görünümleri, Göç, İstiklal Savaşı, Türk Dünyası İzlenimleri olarak tanımlanabilir. Ancak onun tarih ve Orta Asya kokan resimlerine bakıldığında ona Türk mitolojisi ressamı demek daha doğru olur.

İlk dönem çalışmalarında acı, dram, çile, göç ve ayrılık gibi sosyal olguları ele alır. Türk milletinin temel karakterinde var olan kahramanlık ve vatan sevgisi gibi konuları ele aldığ resimleri milli duygu ve değerleri canlı tutmayı hedefler. Anadolu dişında yaşayan bilhassa Orta Asya Türklüğünü de ele alan sanatçı bilhassa Türkistan coğrafyasında çok geniş bir araştırma ve gözlem yapmıştır. Biriktirdiği eskizler bilhassa at figürlerinin etütleri çok realist ve detaylıdır. Atayurt özlemi olarak ele aldığı Orta Asya gözlemleri ve çizimleri Gauguin gibi kendi gerçeklerinden kaçış değil kendi öz benliğine dönüş niteliğindedir (Başbuğ, 2016, s. 25-28). 
Onun resimlerinin konusu içerisinde özel bir yere sahip olan göç ve göçebeler, yoksulluğun, ilkel yaşam koşullarının, kıtlık ve savaşların yansıması göstergelerdir. Ancak yine de bu resimler inancın ve baş eğmezliğin birer göstergesi niteliğindedir (Altıntaş, 2017, s. 68). Mehmet Başbuğ resimleri insan figürlerinin güçlü desen yapısı kompozisyonun bel kemiğini oluşturur. Onun renkleri ve resimsel kurgusu Türk gerçeğinin tanıklıkları ve gelecek kuşaklara aktarılacak belgeleridir (Güngör, 2020, s. 1619).

\section{Mehmet Başbuğ Resimlerinde Hayvan İmgeleri}

Barthes pek çok göstergenin toplumsal kodlardan kaynaklanan yan anlam ve derin anlamlar içerdiğini söyler. Ona göre ilkel toplumlarda balta sahibi olmak aynı zamanda güç ve statü sahibi olmak anlamına da gelir (Gottiner, 2005, s. 32).

Örneğin at binek hayvanı olması yanı sıra pek çok toplumda olduğu gibi Anadolu ve Orta Asya toplumlarında da güç ve statü anlamlarına sahiptir. Türk sanatında aslan, ayı, kurt, köpek, kedi, kartal, şahin, güvercin, geyik, at, koyun, keçi ve balık gibi çok sayıda evcil veya vahşi hayvan imge olarak yer alır. Bu hayvanlar doğada yer alan varlıkları ve doğal görünümleri yanı sıra cesaret, kahramanlık, sadakat ve fedakârlık gibi faklı anlamlara da gönderme yaparlar.

Mehmet Başbuğ’un resimlerinde Türk ve Anadolu kültüründe çok önemli göstergeler olan kurt, köpek, at, eşek, geyik, öküz, kartal, koyun, keçi, horoz gibi bazı hayvanlar özel olarak ele alınmıştır. Bilhassa at figürü Türk kültürü ve mitolojisinde çok önemli bir yere sahiptir.

İnsanoğlunun ilk evcilleştirdiği hayvanlardan birisi olan at, binek hayvanı olmasının yanı sıra insana yakınlığ ve dostluğu ile de bilinir. Savaşlarda bir güç olarak kabul edilmekle birlikte pek çok kültürde manevi ve geleneksel öneme de sahiptir. Pek çok ulusun mitolojisinde ve inanışlarında at önemli bir figür olduğu gibi Türk kültürü ve mitolojisinde de vazgeçilmez kahramanlardan birisidir.

Türk mitolojisinde ve destanlarında at kutsallık atfedilen ve Yaratıcı tarafindan insanın yardımına gönderilen bir hayvan olarak tanımlanır. Hatta insanların öldükten sonra tekrar dirileceğine inancın bir göstergesi olarak eski Türk kurganlarında atların da sahipleriyle birlikte gömüldügü görülür. Türklerin Müslüman olmasından sonra at önemli bir hayvan olmaya devam eder. İslam dini cihadı emrettiği için at da savaştaki rolü nedeniyle yetiştirilmesine ve eğitilmesine çok önem verilen bir canlı olmuştur (Başbuğ, 2012, s. 285).

At gibi bir binek hayvanı olan eşek ve katır daha çok yük taşıma amaçlı olarak kullanılır. Hatta adının Anadolu kültüründe anonim olan işlek kelimesinden geldiği söylenir. Bilhassa engebeli arazilerde binek olarak kullanılmaya attan daha uygundur. Dirençli ve güçlü yapısı yanı sıra inatçıllğ̆1 ve direniş göstermesi de meşhurdur. Ayrıca sesi ve anırması da Anadolu kültüründe çeşitli anlamlar ifade eder. Hatta Kuran'da eşek sesi en kötü ses olarak tarif edilir "O hâlde yürüyüşünde mutedil ol; sesini de alçalt! Çünkü seslerin en çirkini, elbette eşeklerin sesidir!” (Lokman, 31/19).

Koyun ve keçiler Türk kültüründe özelikle göçebe topluluklarda vazgeçilmez yaşam kaynaklarıdır. Koyun ve keçi, Türk kültür ve sanatı içerisinde sembolik bir yere sahiptirler. Ayrıca Orta Asya’nın büyük bir bölümünde tarıma ve yerleşik hayata elverişli olmayan bozkırlarda geçimini sağlamak için yetiştirilen önemli bir hayvanlardır.

Güngör (2019, s. 28) keçinin bilhassa Yörük toplumu için önemini Sarıkeçili veya Karakeçili gibi Yörük boy isimleriyle vurgular. Anadolu insanı için günlük yaşamın vazgeçilmez uğraşlarından koyun ve keçilerle yaylaya göç etme Mehmet Başbuğ un resimlerinde, insanlar ve hayvanlar için değişmez bir süreci kapsar (Tepecik, 2017, s. 74).

Öküz, inek ve boğa da Anadolu ve Asya toplumlarında kutsal ve mübarek görülen hayvanlardır. Bu hayvanların antik Mısır, Hindistan ve Ortadoğu'da kutsallaştırılarak bir tapınma aracına dönüştürüldüğü Kuran'da bile yer alır (A'râf, 148) Mehmet Başbuğ resimlerinde inek veya öküz bilhassa Anadolu halk kültürüne gönderme yaparak itaat ve bereket göstergesidir. Bilhassa Kurtuluş savaşı resimlerinde kağnıları çeken öküzler milli birer simge olmuşlardır.

Türk tarihinde ve mitolojisinde kartal özel bir yere sahiptir. Kartal, Orta Asya Türk topluluklarında koruyucu ruh, asalet, güç ve kudret göstergesi olarak kabul edilir. İslâmiyet'ten sonra da kartal önemli bir sembol olmaya devam eder. Bilhassa çift başlı kartal doğu ve batının hâkimi olmaya gönderme yapar (Çoban, 2015, s. 59-60). 
Mehmet Başbuğ’un resimlerinde gökyüzünde uçan kartal figürü Türk kültüründe gökyüzünün hâkimi, güç, kuvvet ve kudret göstergesi olarak görünür. Açık-koyu, boşluk-doluluk gibi kompozisyon ögelerinin dengesi için odak noktalarına yerleştirilen bu figürler aynı zamanda resimlerin plastik bir öğesi durumundadır.

Kurt veya Bozkurt Anadolu ve Orta Asya Türk kültürüne özel bir yere sahiptir. Anadolu kültüründe canavar olarak tanımlanan kurt koyun ve keçi sürülerini telef etmesi ile bilinir. Ancak Türk mitolojisinde yol gösterici, kutlu kurt gibi unvanlara sahiptir. Göktürklerin gök (mavi) bayraklarında kurt kafası vardır. Savaşç1 özgür ruhu temsil eder. Bozkurt, Türklerin mitolojik sembolüdür ve Tarih öncesi çağlardan beri kutsal sayılır. Türeyiş destanı ve Ergenekon'dan Çıkış destanlarında kurt bilhassa Aşina (dişi kurt) önemli bir yere sahiptir. Ayrıca Kırgızlar'da kahramanlar Kökbörü (Bozkurt) olarak adlandırlır (Topsakal, 2019, s. 79-80).

Kurdun vahşiliğine zıt olarak köpek insanlara dost ve yardımc1 evcil bir hayvandır. Özellikle çobanların sürüleri gütmesinde ve korumasında en büyük yardımcısıdır. Ayrıca avcılıkta da insanlara yardım ederler. Köpeklerin can ve mal güvenliğinde de önemli bir yeri vardır. Türk kültüründe köpek dostluk, sadakat, itaat ve güven göstergesidir.

Mehmet Başbuğ’un Orta Asya temalı bazı resimlerinde geyik de yer alır. Geyik bilhassa Sibirya taraflarında hem kutsal hem de önemli bir hayvandır. Eski şamanların yanında yer alır. Bolluk ve bereketin sembolü olması yanı sıra yol gösterici mübarek bir hayvan olarak görülür (Çatalbaş, 2011, s. 54).

Mehmet Başbuğ resimlerinde horoz gibi kümes hayvanları da görülmektedir. Horoz ve tavuk gibi evcil kümes hayvanları Anadolu köy kültürünün vazgeçilmez yaşam unsurlarıdır. Tarım ve hayvancilı̆̆n önemine vurguladığ1 gibi horozun sabahları erkenden öterek insanları uyandırması, erken kalkmak, erkenden yol almak ve çalışmaya başlamak, hatta sabah namazına kalkmak gibi ortak kodlarımıza gönderme yapar.

\section{MEHMET BAŞBUĞ BOZKIRDAKI ATLAR / Desenler}

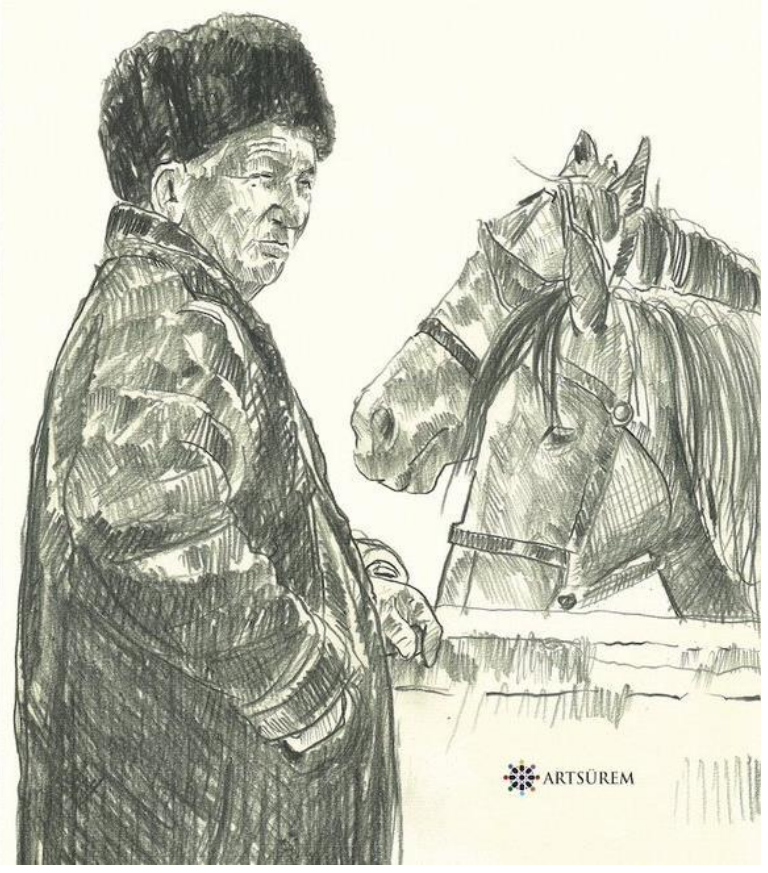

Görsel 2. Mehmet Başbuğ'un At Desenlerinden Olusan "Bozkerdaki Atlar" Kitabı 


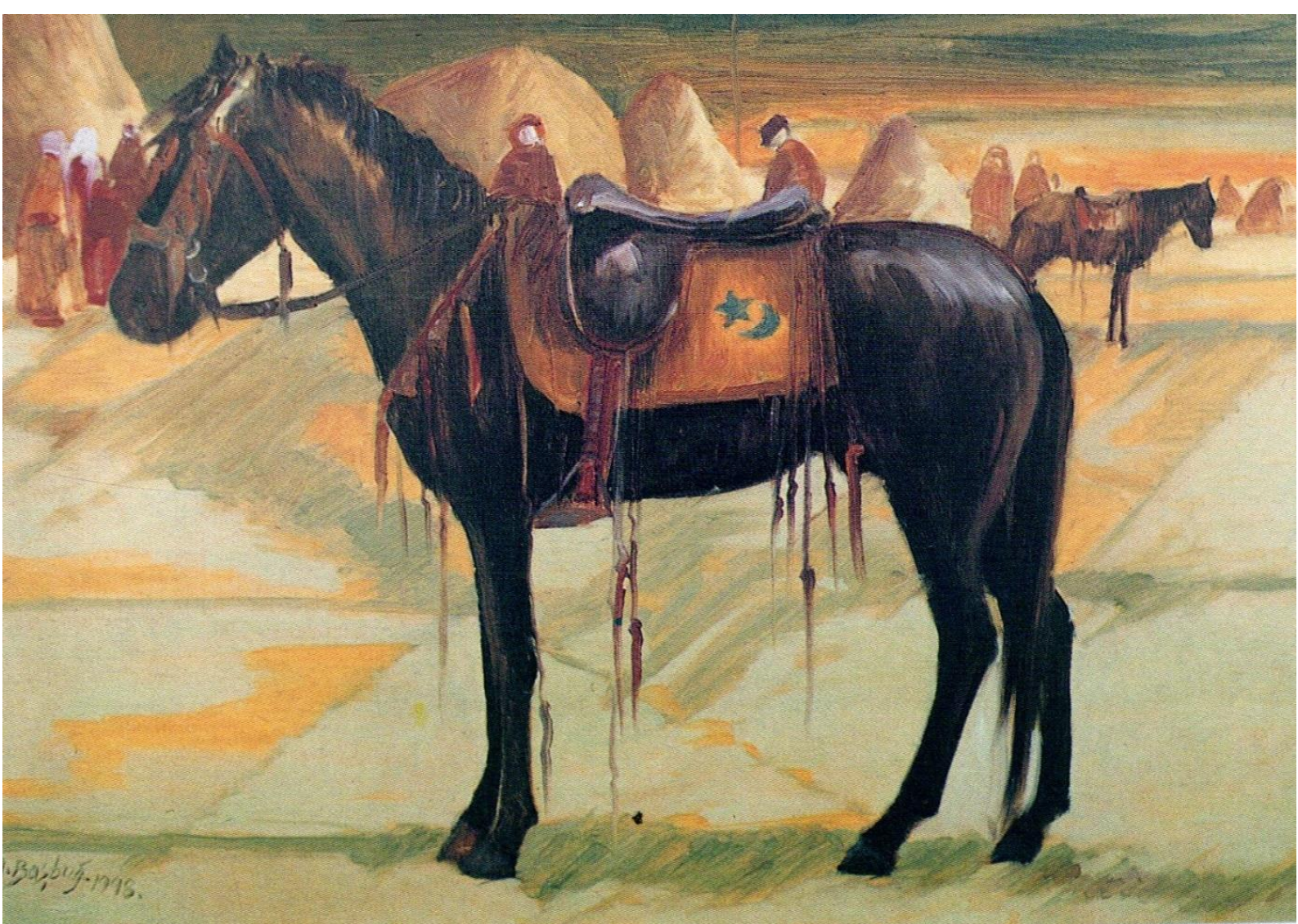

Görsel 3. Mehmet Başbŭg, "Hasat”, $50 \times 70$ cm, Tüyb, 1999 (Sergi Katoloğu, 2000, s. 16)

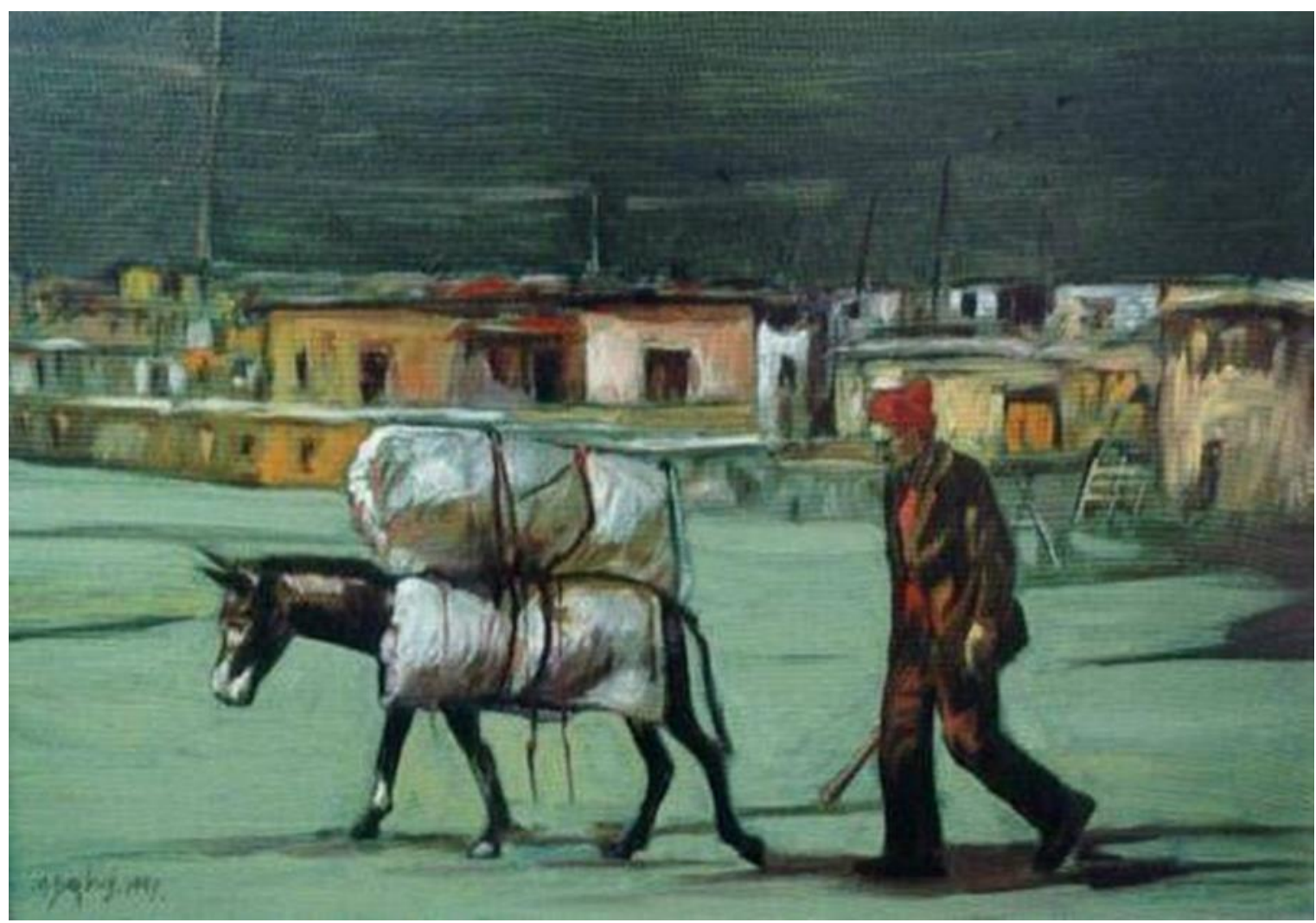

Görsel 4. Mehmet Başbuğ, Köyden Görïnüs,s, 1998, $50 x 70$ cm. (Sergi Kataloğu, 2000, s. 13) 


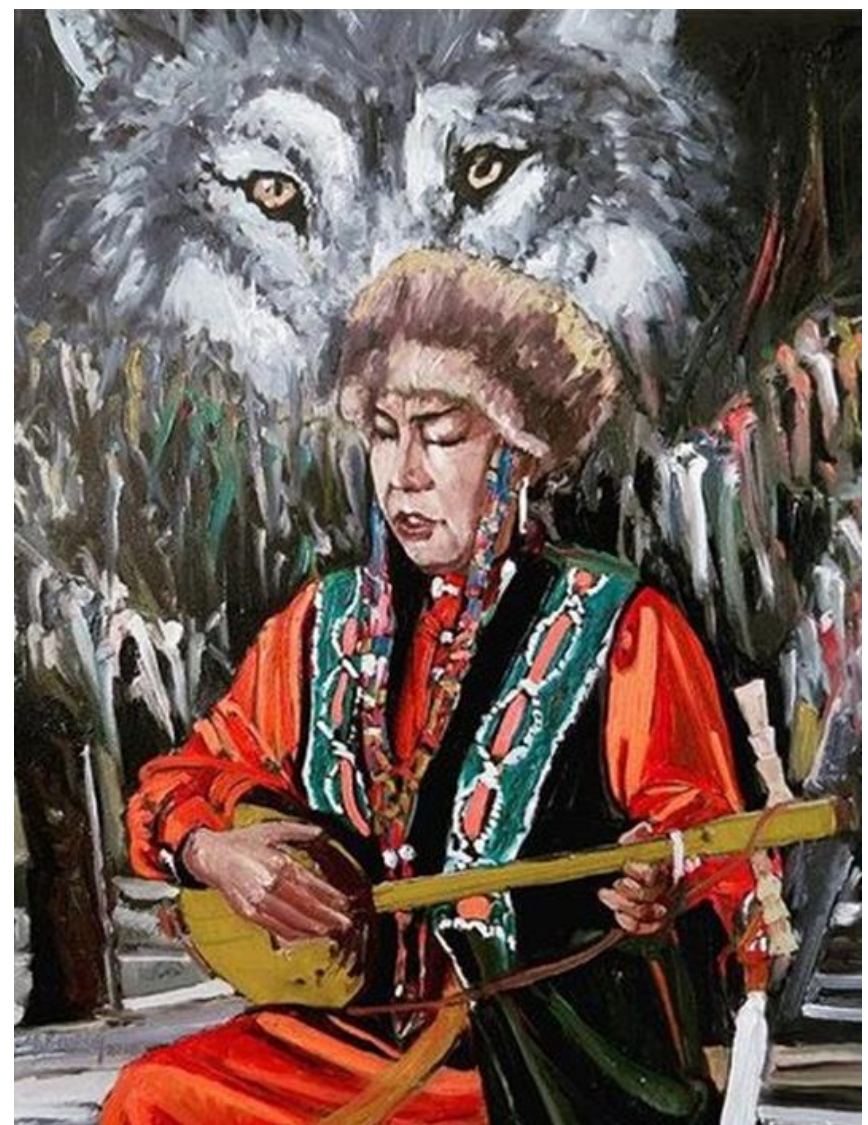

Görsel 5. Mehmet Başbuğ Resminde Kurt, 2016 (Sibirya Araştrrmalan Dergisi Kapağt, 2016/9)

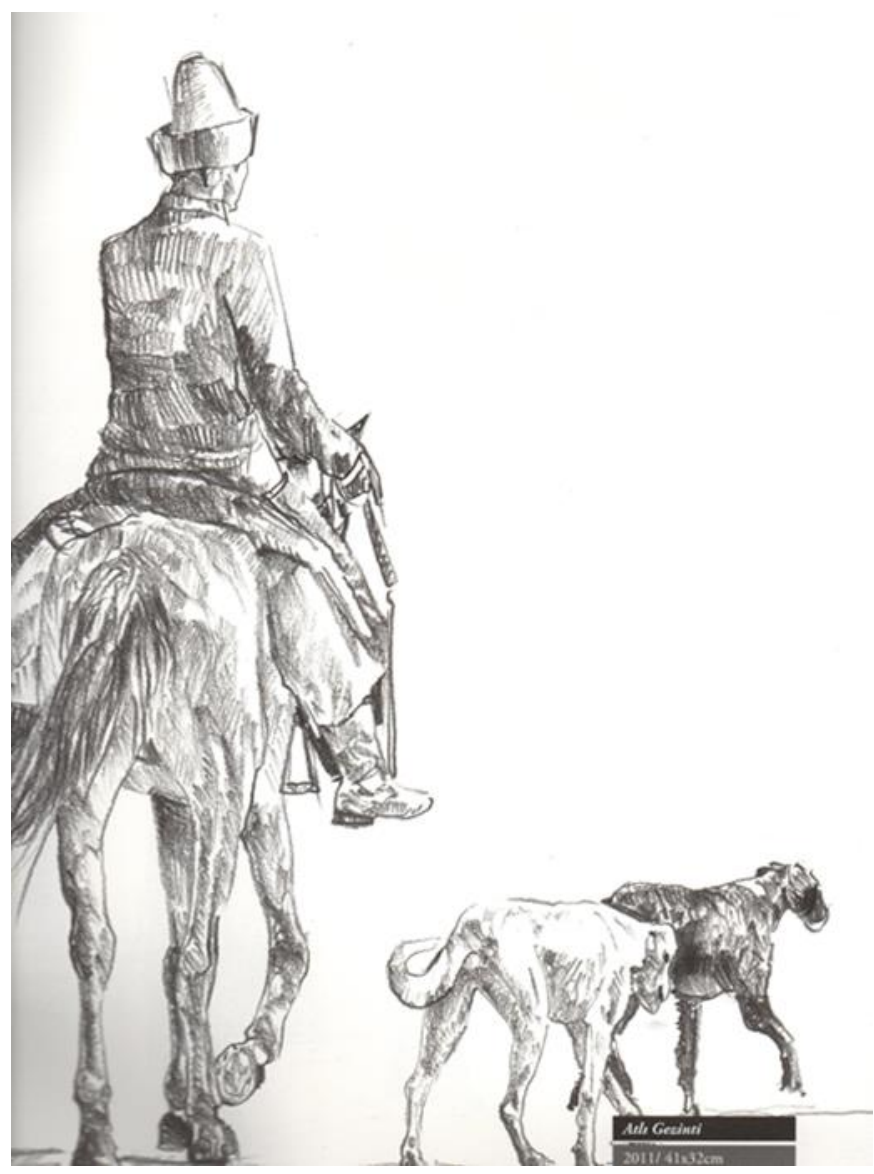

Görsel 6. Mehmet Başbuğ Resminde Köpekler, Ath Gezinti,2011, 41 x32 cm. (Başbŭg, 2016, s. 115) 


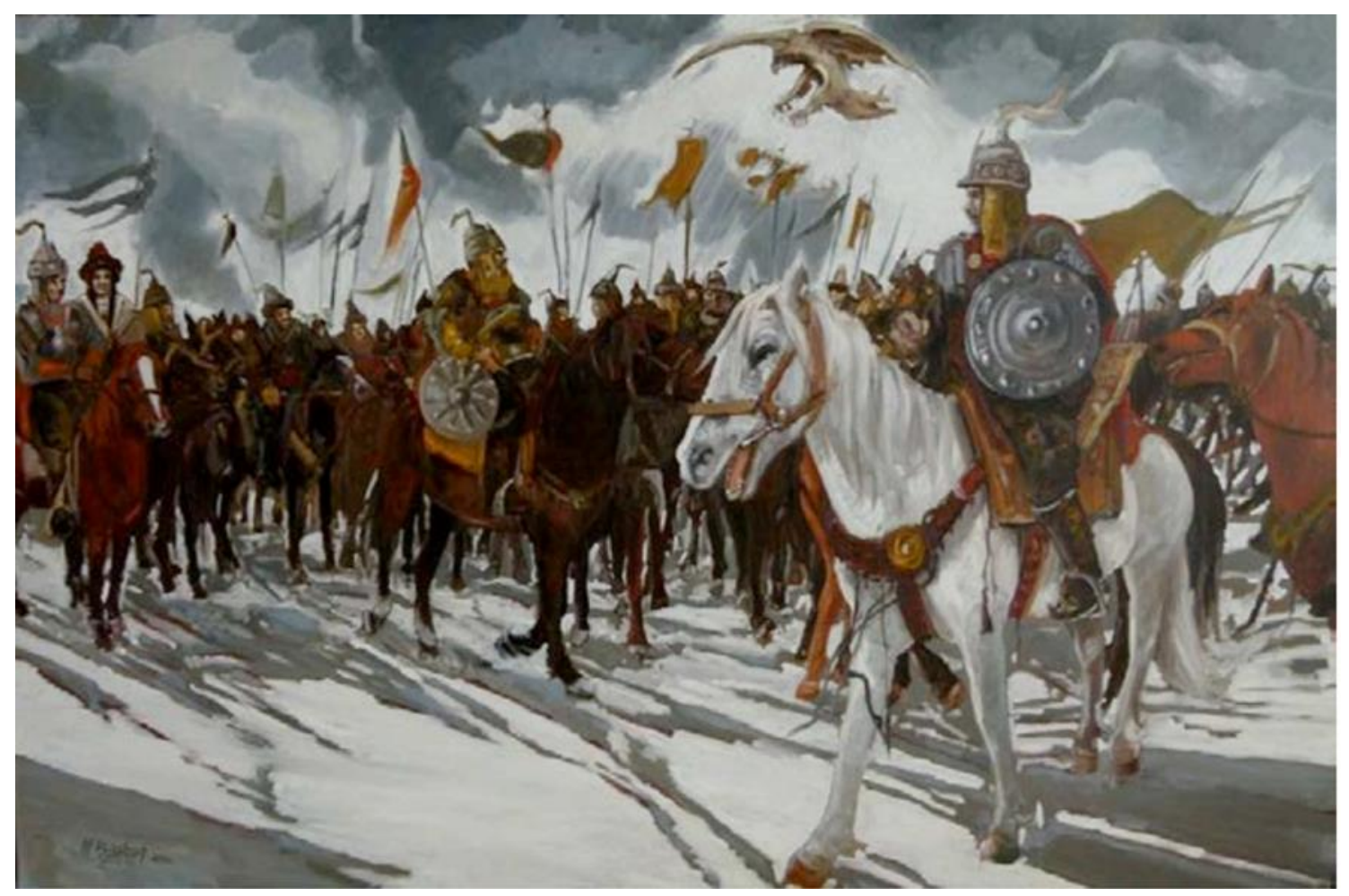

Görsel 7. Mehmet Başbuğ Resminde Kartal, "Manas Destam”, 2011, Tuval Üzৃerine Yağh Boya, 100×150 cm. (Coban, 2015, s. 73)

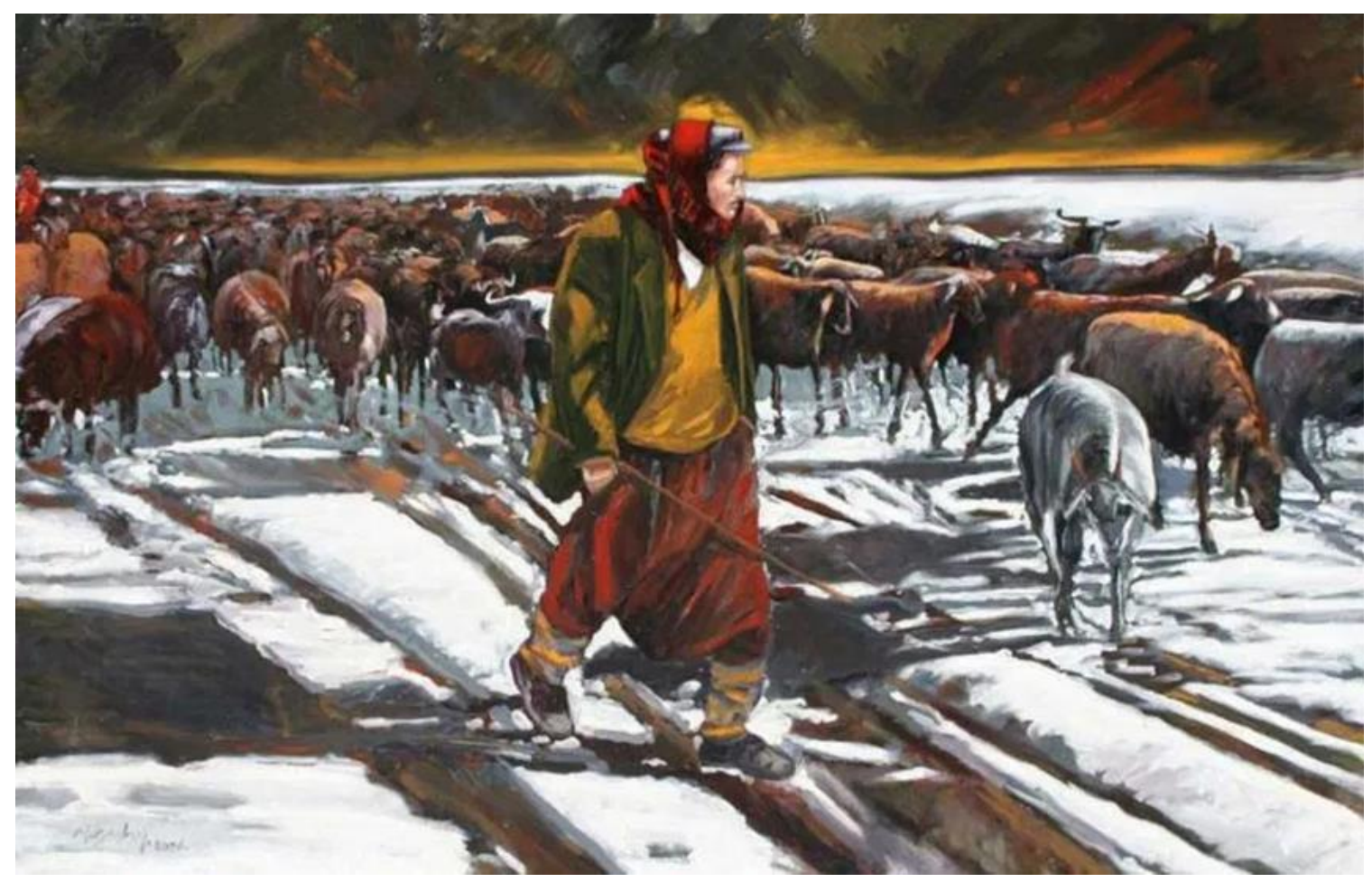

Görsel 8. Mehmet Başbuğ Resminde Koyunlar, 2007, 140×200 cm. (Güngör, 2018, s. 207) 


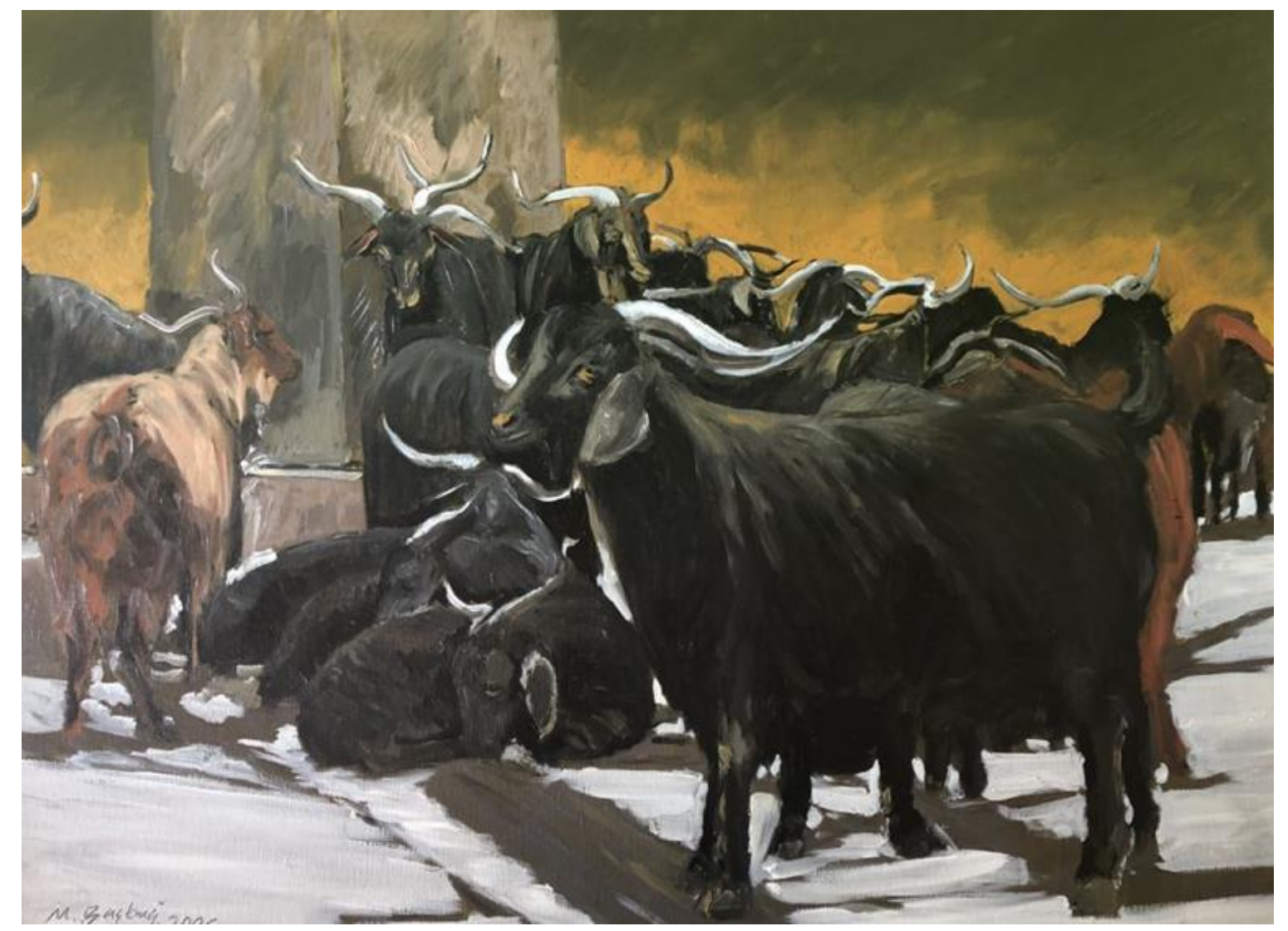

Görsel 9. Mehmet Başbuğ, "Keçiler", 60x80 cm, TÜYB, 2005 (Dalkiran ve Bayrak, 2019, s. 33)

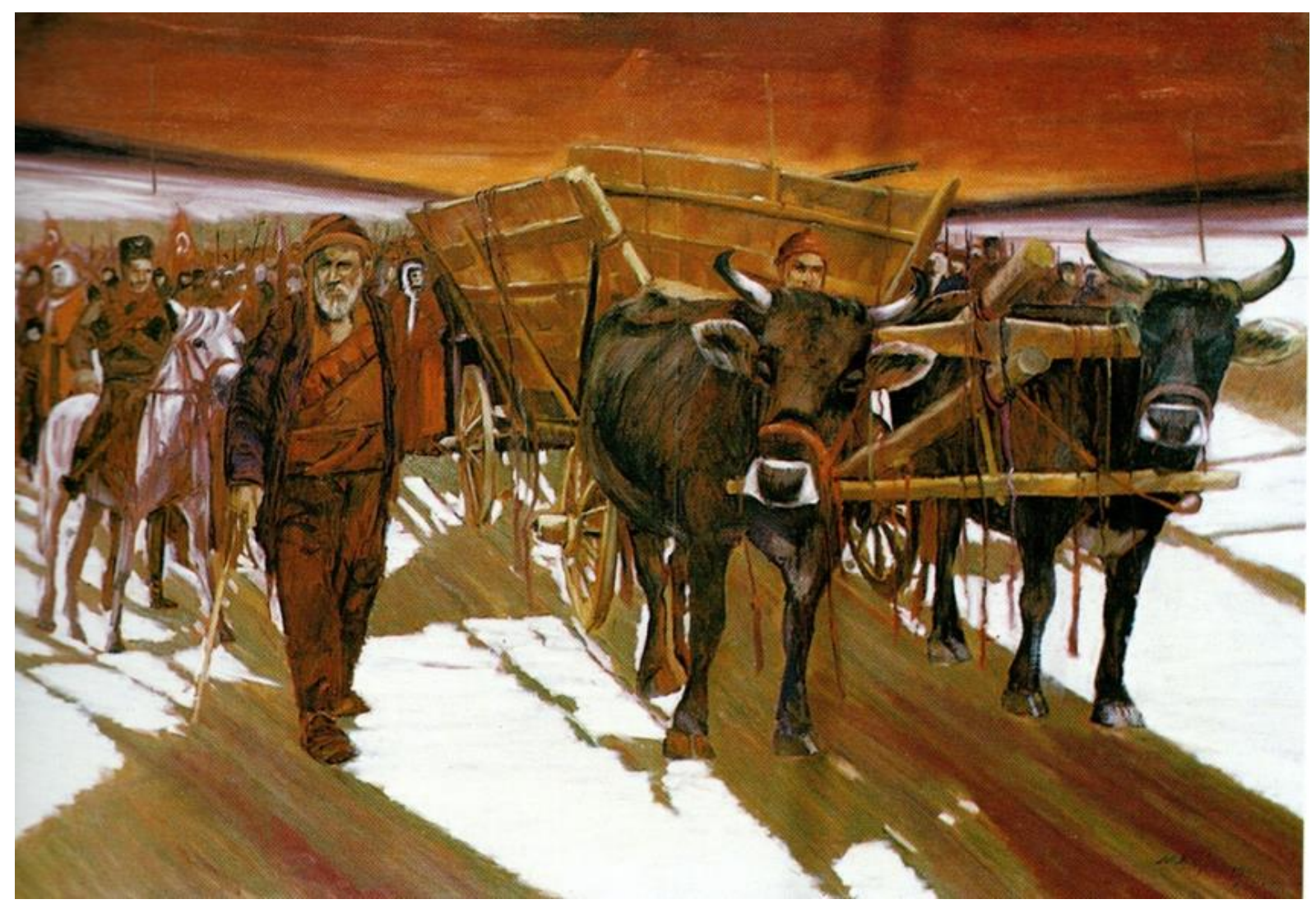


Görse1 10. Mehmet Başbuğ Resminde Öküzler, Kurtuluş Savaşında Kağnular, 1998. $140 \times 200$ cm. (Sergi Kataloğu, 2000, s. 19)

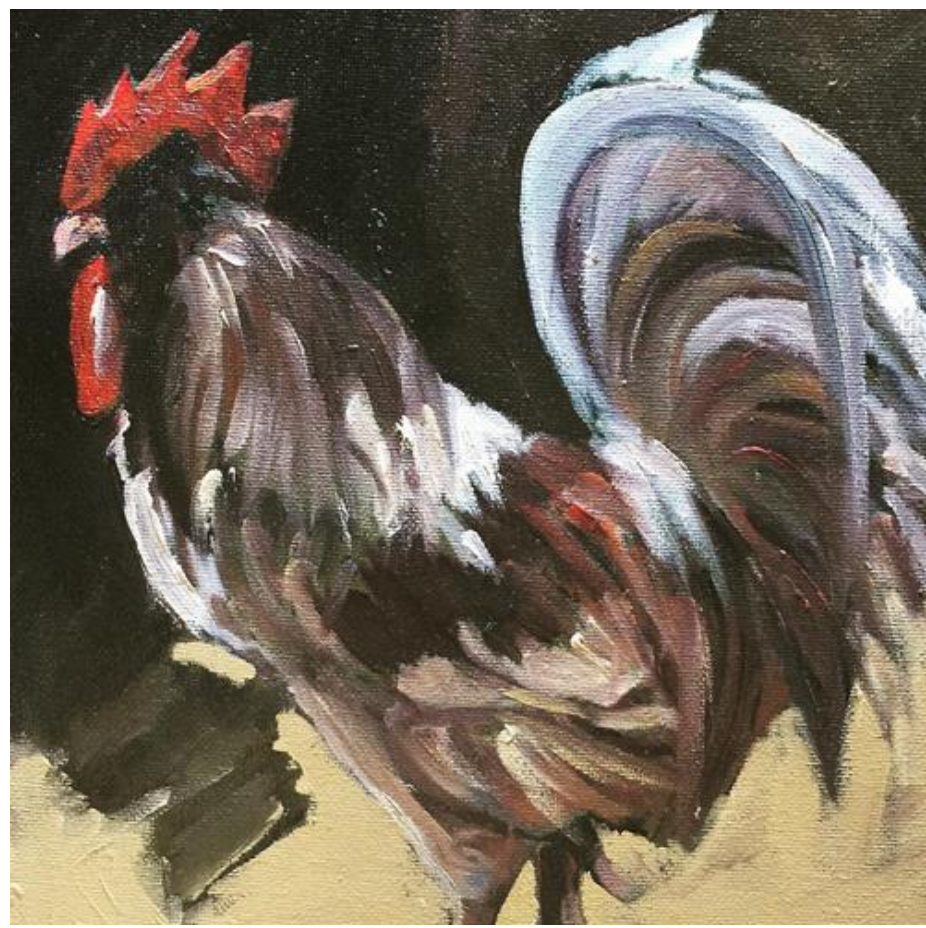

Görsel 11. Mehmet Başbuğ Resminde Horoz, https:// www.instagram.com/p/BIre5Tqhjg// (24.01.2021)

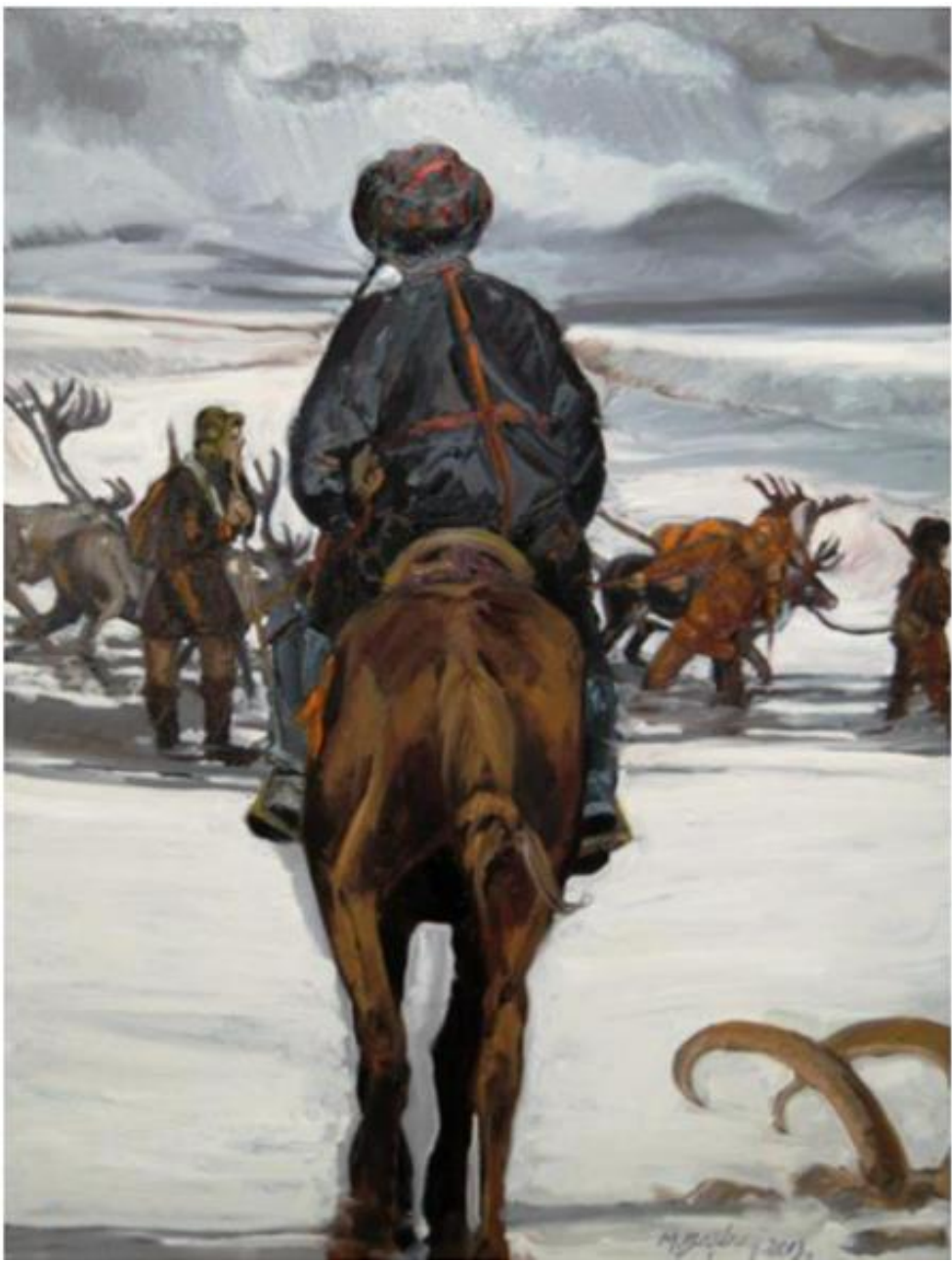


Görsel 12. Mehmet Başbuğ Resminde Geyikler, Soğuk Bir Kıș Hikayesi (Sibirya'dan) 2013, $80 x 60 \mathrm{~cm}$ (https://www.artsurem.com/art/artist/mehmet-basbug/5/30.09.2020)

\section{Mehmet Başbuğ Resimlerindeki Hayvan İmgelerinin Göstergebilim Çözümlemesi}

\section{Resimdeki Göstergeler}

Mehmet Başbuğ resimlerinde tasvir edilen hayvan imgelerinden bazıları aşağı da birer gösterge olarak ele alınacak ve düz anlam, yan anlam ve derin anlam şeması ile çözümlenecektir.

At pek çok toplumda olduğu gibi Anadolu ve Orta Asya toplumlarında da güç ve statü anlamlarına gelir. Ayrıca dostluk, arkadaşlık, cesaret, mertlik ve fedakârlık göstergesidir.

Eşek binek hayvanı olmakla birlikte bir gösterge olarak çalışkanlık, iş gücü, dayanıklılık, sabır ve inatçllık gibi anlamlara gönderme yapar. Koyun: İtaat ve bereket göstergesidir.

Koyun ve keçi Türk kültüründe bilhassa Orta Asya'dan başlayarak Anadolu’ya gelinceye kadar göçebe topluluklarda çok önemli bir yere sahiptir. Bir gösterge olarak ele alındı̆̆ında koyun hem bolluk, bereket hem de itaat anlamlarına gönderme yapar. gösterir.

Keçi bereket ve bolluk yanı sıra inatç1lıkta da simgesel bir yere sahiptir. Ayrıca direnç ve direnişi de

Kurt Roma’nın kuruluşunda olduğu gibi Orta Asya Türk kültüründe de özel simgesel anlamlar taşır. Türk mitolojisinde başlang1ç, Ergenekon'dan çıkış, cesaret, yiğitlik, dostluk ve mertlik simgesidir.

Köpek, çobanların yardımcısı hem avlanırken insanlara yardımcı olması hem de güvenlik amacıyla beslenmesi gibi özellikleri olan evcil bir hayvandır. Köpek bir gösterge olarak dostluk, sadakat, itaat ve güven kavramlarına gönderme yapar.

Kartal da Türk kültüründe sembolik anlamlar taşıyan bir göstergedir. Özellikle çift başlı kartal bayraklardan Türk motiflerine kadar Türk sanatında çok göze çarpar. Çift başlı kartal doğunun ve batının hâkimi. Kartal hem özgürlük hem de hâkimiyet göstergesidir. Gökyüzünün hâkimi, güç, kuvvet ve kudret göstergesi.

Öküz, inek ve boğa bilhassa antik Mısır ve Hindistan toplumlarında kutsallık atfedilen bir hayvandır. Mehmet Başbuğ resimlerinde inek veya öküz bilhassa Anadolu halk kültürüne gönderme yaparak itaat ve bereket göstergesi olur.

Geyik özellikle dünyanın Kuzey bölgelerinde kutsal bir hayvandır. Eski şamanların yanında yer alır. Bolluk ve bereketin sembolü olması yanı sıra yol gösterici bir hayvan olarak görülür.

Horoz, bilhassa Anadolu kültüründe sabahları erkenden ötmesi ile sabahın, zamanın, çalışmanın ve güne başlamanın göstergesidir.

Tablo 1. Göstergebilim Anlam Çözümleme Şeması (Soylu, 2018, s. 43-45)

\begin{tabular}{|c|c|c|c|}
\hline Gösterge & Düz Anlam & Yan Anlam & Derin Anlam \\
\hline At & $\begin{array}{l}\text { Canl, Evcil Hayvan, } \\
\text { Binek }\end{array}$ & $\begin{array}{l}\text { Yardımc1, Dostluk, Sadakat, Vefa, Savaş } \\
\text { Gücü, Özgürlük }\end{array}$ & Mitoloji, Kültür, İdeoloji, Tarih \\
\hline Eşek & $\begin{array}{l}\text { Canl, Evcil Hayvan, } \\
\text { Binek }\end{array}$ & $\begin{array}{l}\text { Çalışkanlık, İş Gücü, İnatçlık, } \\
\text { Dayanıklılık, Sabır }\end{array}$ & $\begin{array}{l}\text { Göçebelik, Anadolu Halk } \\
\text { Kültürü }\end{array}$ \\
\hline Kurt & Canl, Yabani Hayvan & Cesaret, Yiğitlik, Dostluk & Mitoloji, Kültür, İdeoloji, Tarih \\
\hline Köpek & Canl1, Evcil Hayvan & Dostluk, Güven, Güvenlik, Sadakat & Mitoloji, Kültür, İdeoloji \\
\hline Kartal & Canli, Yabani Hayvan & Özgürlük, Bağımsızlık, Hakimiyet & Mitoloji, Kültür, İdeoloji, Tarih \\
\hline Koyun & Canl, Evcil Hayvan & Bereket, Bolluk, Rızık, İtaat & $\begin{array}{l}\text { Göçebelik, Anadolu Halk } \\
\text { Kültürü }\end{array}$ \\
\hline Keçi & Canl1, Evcil Hayvan & $\begin{array}{l}\text { Bereket, Bolluk, Rızık, İnat, Direniş, } \\
\text { Direnç }\end{array}$ & $\begin{array}{l}\text { Göçebelik, Anadolu Halk } \\
\text { Kültürü }\end{array}$ \\
\hline Öküz & Canl, Evcil Hayvan & $\begin{array}{l}\text { Ağır Yük, Direniş, Bereket, Bolluk, } \\
\text { Kutsallı }\end{array}$ & Mitoloji, Kültür, Din \\
\hline Geyik & Canl, Yabani Hayvan & Direniş, Cesaret, Güç, Kuvvet & $\begin{array}{l}\text { Orta Asya Türk Kültürü, } \\
\text { Şamanlık }\end{array}$ \\
\hline Horoz & Canl, Evcil Hayvan & $\begin{array}{l}\text { Sabah, Uyanış, Güne Başlamak, } \\
\text { Çalışmak, Zaman }\end{array}$ & Anadolu Halk Kültürü, \\
\hline
\end{tabular}


Tablo 2. Karşıt Anlamlar Şeması (Soylu, 2018, s. 43-45)

\begin{tabular}{ll}
\hline Varlık & Yokluk \\
\hline Özgürlük & Esaret \\
\hline Cesaret & Korkaklık \\
\hline Aktif & Pasif \\
\hline Güzellik & Çirkinlik \\
\hline Değerli & Değersiz \\
\hline Fakirlik & Zenginlik \\
\hline Şuur & Şuursuz \\
\hline Madde & Mana \\
\hline Yaşam & Ölüm \\
\hline Sadakat & Sadakatsizlik \\
\hline İtaat & İaatsizlik \\
\hline İnat & Sebat \\
\hline Direniş & Teslimiyet \\
\hline Güven & Güvensizlik
\end{tabular}

Tablo 3. Greimas'in Eyleyenler Şeması Uygulaması (Soylu, 2018, s. 43-45)

Hayvan Sevgisi

Gönderici

Türk Kültürü

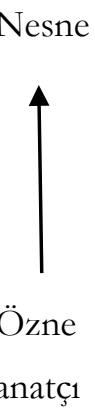

Alic1

Toplum

Karşı çıkan

Hayvan Düşmanlığ1

Tablo 4. Göstergebilimsel Dörtgen Uygulama Şeması (Kıran, 2013, s. 385)

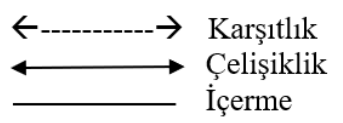

Evrensel

$\mathrm{S}_{1}$

Yerli

Milli

$\mathrm{S}_{1}$

Yabanc1 Deği

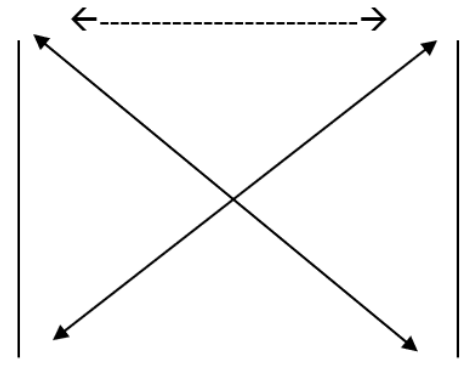

$\leftarrow$

$$
\text { Ś }
$$

$\mathrm{S}_{2}$

Yerli Değil

S2

Yabanc1

İthal

F1tri-Doğal 
Tablo 5. Göstergebilimsel Dörtgen Uygulama Şeması (Gremias,1987, s. 110)

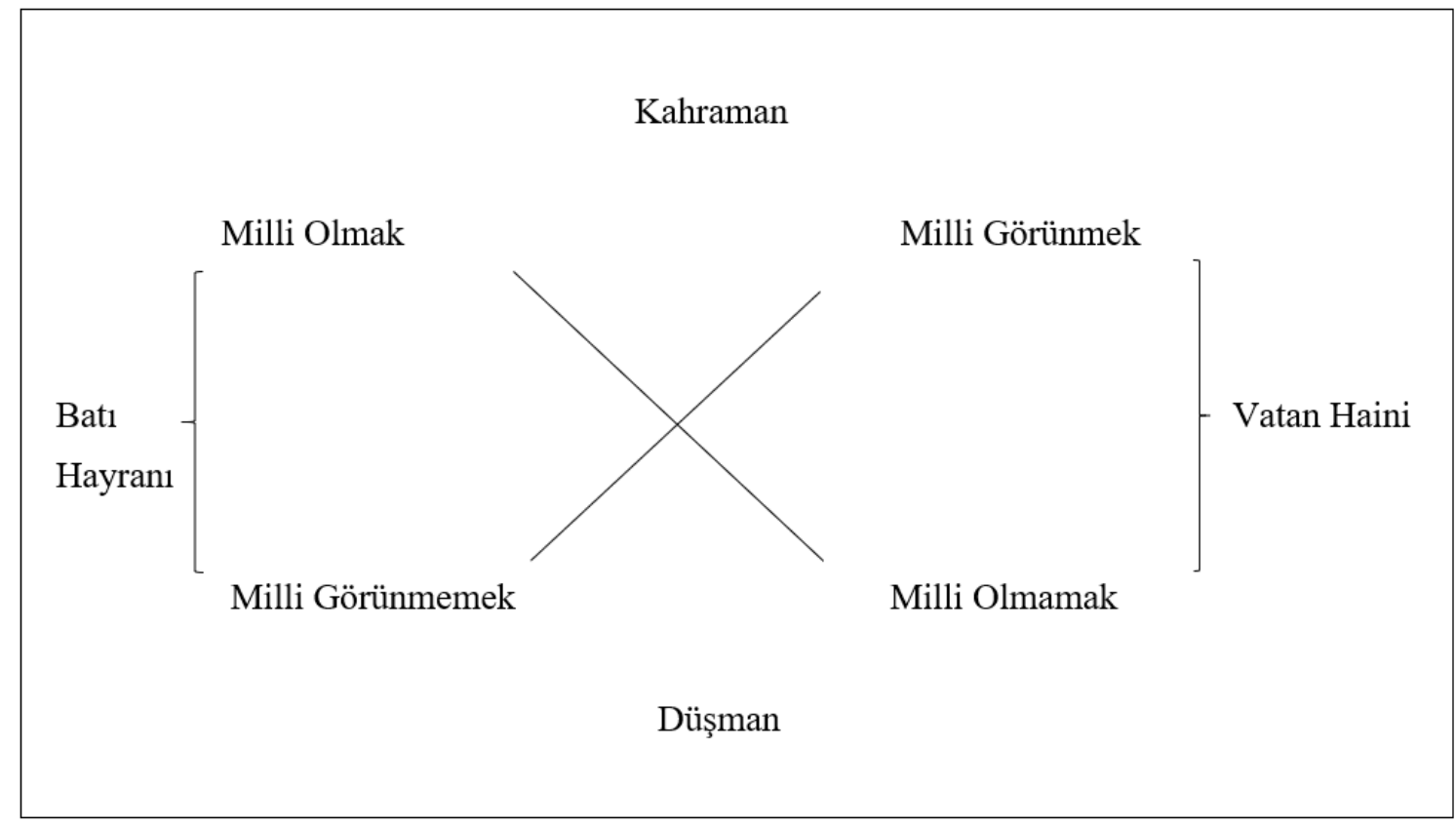

Tablo 6. Göstergebilimsel Dörtgen Uygulama Şeması (Kıran, 2013, s. 385)

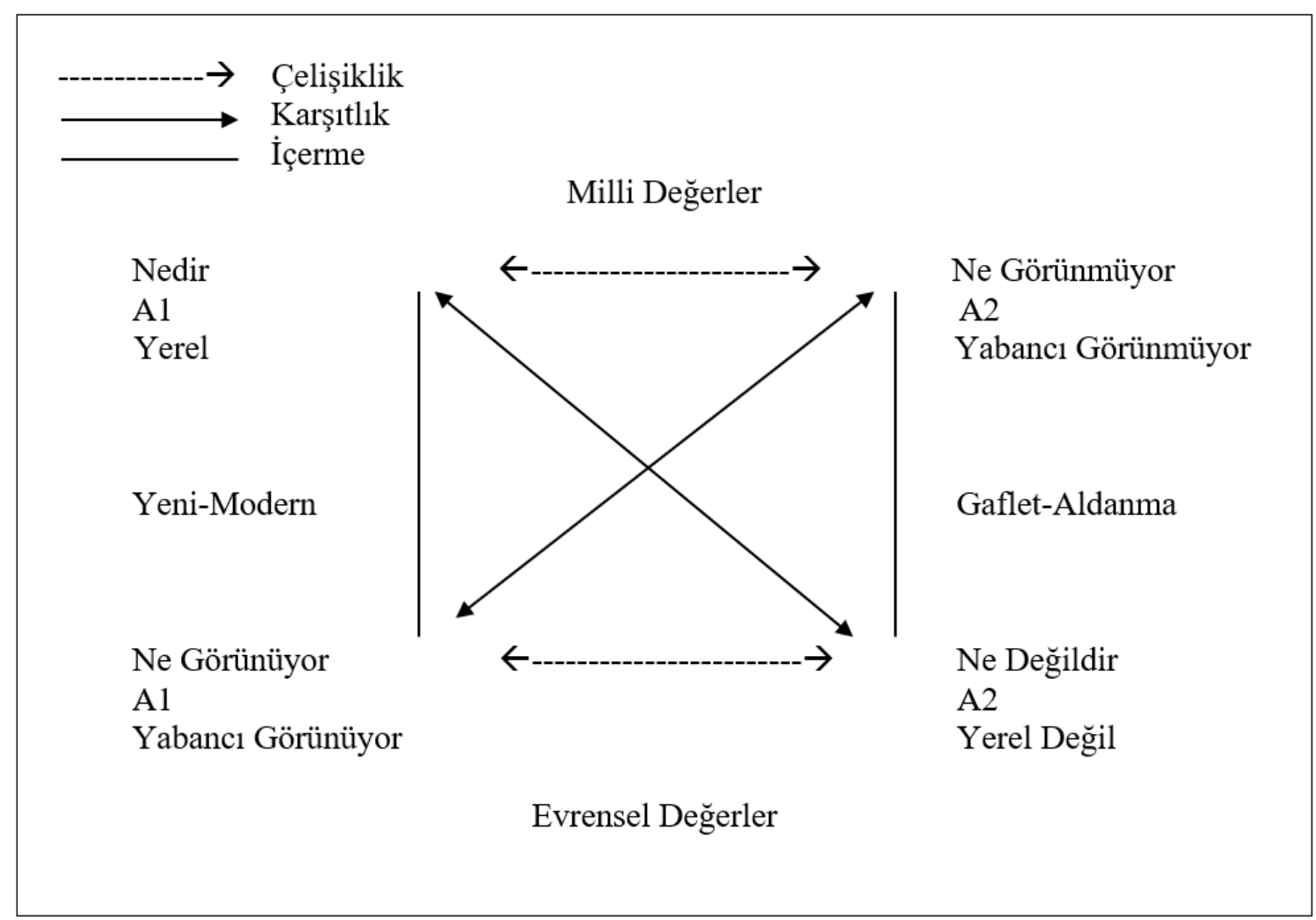

Bu şema şöyle somutlaştırılabilir.

A1 A2 
Yerel olan ve yabanc1 görünmeyen şey milli yani ulusaldır. Bize öz ve özgü olan milli değerler ve ulusal sanat gibi. Mehmet Başbuğ resimlerinde çoklukla görülen Anadolu ve Türk kültürüne özgü figürler milli duygu ve değerlerimizi yansitır.

A1_- --- A2

$\mathrm{Bu}$ önermede ise yabancı görünen ve yerel olmayan şey ya yabancıdır veya evrensel olabilir. Batı sanatı veya evrensel kültür gibi. Tabi ki bazen yerel olan bir şey evrensel kültüre de mal olabilir. Hayvan sevgisi evrenseldir. Ancak Türk kültüründe bilhassa at ve kartal gibi bazı hayvanlar özel bir öneme sahiptir. Bazen de evrensel kültür içerisinde yer alan domuz ve fare gibi bir figür bizim kültürümüze yabancı olabilir.

A1 A1

Üçüncü önermede yerel olan ancak yabanc1 görünen şey, yeni bir şeydir ve belki modern olarak tanımlanabilir. Burada da bazı yenilikler ilk başta yabancı gibi görülebilir. Ancak her kültürde yenilikler modernizmin kaçınılmaz sonucudur. Örneğin kımız ve kefir Orta Asya'dan 1990’lı yıllarda ilk geldiğinde yabancı ve garip karşılanmış ancak zaman içerisinde bunların Türk kültürünün bir parçası olduğu anlaşılmıştır. Gerçi bunlar yeni ve modern şeyler değildir ancak bizim için yenidir.

\section{A2_ $\mathrm{A} 2$}

Son önermede ise yabancı görünmeyen ancak aslında yerel de olmayan şey milli değerler arasına sızmış gaflet ve aldatıcı olan bir şeydir. Bazen de sömürgeci emperyalist devletlerin sömürdükleri toplumlara dayattığı kültür emperyalizminin sonucu olarak yabancı olan ve milli olmayan bazı şeyleri bir topluma çeşitli propaganda araçlarıyla milli gibi dayatılmalarıdır. Noel Baba ve Yılbaşı çamı örnek olarak verilebilir.

\section{Sonuç}

Mehmet Başbuğ son dönemde Türkiye'de olduğu gibi Orta Asya Türk devletlerinde de tanınan bir ressamdır. Özellikle Kırgızistan Türkiye Manas Üniversitesi Güzel sanatlar Fakültesi’nde sanat eğitimciliği ve Dekanlık görevi sürecinde Türk kültürünü yakından inceleme firsatı bulmuş ve gözlemlerini devasa resimlerle ölümsüzleştirmiştir. Ayrıca Türk kültürünün köklerine inmiş, Orta Asya ile ortak kodlarımızı da yakından incelemiştir. Resimlerinin çoğunda acı, dram, çile, göç ve ayrılık gibi konuları ele almakla beraber Türk milletinin özünde var olan cesaret, yiğitlik, mertlik, kahramanlık ve vatan sevgisi gibi konuları da ele alarak milli duygu ve değerleri gelecek kuşaklara miras bırakacak büyük eserler ortaya koymuştur.

Ömrünü Türk dünyası ve Türk kültürüne adayan Mehmet Başbuğ, resimlerinde gerek Anadolu gerekse Orta Asya Türk kültürüne ait imge ve izleklere ayırmış bir ressamdır. Onun resimlerinde insanların yüzleri ve elleri, çalışan, üreten, çile çeken insanların cesaret, mertlik ve yiğitlik göstergeleridir. Aynı şeklide onun resimlerinde yer alan hayvanlar da canlı olma düz anlamı yanı sıra bereket, cesaret, güç, kuvvet ve itaat göstergesi olarak da yer alır. Bunların göstergebilimin yöntemi ile incelenmesiyle görünen düz anlamları yanı sıra yan anlamları ve derin anlamları da ortaya çıkar.

Mehmet Başbuğ resimlerinde hayvan imgeleri gösterge olarak ele alındığında, Türk kültürü içerisinde yerel olan ancak evrensel anlamlar da içeren birer sembol olarak düşünülebilir. Göstergebilimde göstergeler karşıt anlamlarını da çağrıştırır ve gönderme yapar. Bu bağlamda Mehmet Başbuğ resimlerinde milli kültür simgeleri ulusal olmayan ya da düşman olan ve öz değerlerine zarar verebilecek şeylere karşı bir uyarıc1 niteliğindedir. Bu semboller yeni ve modern olanı dışlamamakla birlikte milli ve yereli koruma bilinci kazandirır.

Sonuç olarak Mehmet Başbuğ Türk kültürünün köklerine ve ortak kodlarına gönderme yapan imge ve sembolleriyle çağdaş Türk sanatında önemli bir yer edinmiş bir sanatçıdır. Onun resimleri sadece bir tasvir veya doğa etüdü olmaktan çok yan anlamlar ve derin anlamlar içeren göstergeler taşır. Ele aldığı konular ve işlediği figürler Türklük bilincine gönderme yapar. Hem yaptı̆̆ı resimler hem de güçlü eğitimci kişiliği ile yetiştirdiği öğrenciler onun en büyük eserleridir.

\section{Etik Beyan}

"Mehmet Başbuğ Resimlerinde Hayvan İmgelerinin Göstergebilim Çözümlemesi” başlıklı çalışmanın yazım sürecinde bilimsel kurallara, etik ve alınt kurallarına uyulmuş; toplanan veriler üzerinde herhangi bir tahrifat yapılmamış ve bu çalışma herhangi başka bir akademik yayın ortamına değerlendirme için 
gönderilmemiştir. $\mathrm{Bu}$ araştırma doküman incelemesine dayalı olarak yapıldığından etik kurul kararı zorunluluğu bulunmamaktadır.

\section{Kaynakça}

Akerson, F. E. (2006). Göstergebilime giriş. İstanbul: Multilingual Yayınları.

Altıntaş, O. (2017). Tanrı dağları sonsuza kadar yaslı kaldı. Türk Yurdu Dergisi, 360, 68-69.

Aytekin, O. (2006). Çile ve umudun ressamı mehmet başbuğ ile sanatı üzerine. Genç Kardelen Kültür Sanat Edebiyat Dergisi, 11 (Kasim). 20-23.

Başbuğ, F. (2009). Çağdaş Türk resminde at tasvirleri. Türk-İslam Medeniyeti Akademik Arașttrmalar Dergisi, 8, Yaz, Konya -2009

Başbuğ, F. (2016). Mebmet Başbuğ - Bozkkrdaki Atlar/ Desenler. Akara: Artsürem.

Başbuğ, T. (2012). Çağdaş Türk resim sanatında at tasvirleri. İdil Dergisi , 1(5), 282-306.

Başkan, S. (1991). On dokuгuncu yürynldan günümü̈ze Türk ressamlar. Ankara: Kültür Bakanlı̆̆1 Yayınları.

Çatalbaş, R. (2011). Türklerde hayvan sembolizmi ve din ilişkisi. Turan Stratejik Araştrmalar Merkęi Dergisi, 3(12), 4960.

Çoban, İ. (2015). Türk ikonografisinde kartal motifi ve çağdaş Türk resmine yansımaları. İdil Dergisi, 4(16), 57-75.

Dalkıran A. ve Bayrak, T. (2019). Türk kültüründe keçinin yeri ve Mehmet Başbuğ resimlerindeki yansımaları. Taribin Peşinde Uluslararası Tarih ve Sosyal Arasturmalar Dergisi, 22, 25-35.

Eco, U. (1992). Açle yapıt (Çev: Y. Şahan). İstanbul: Kabalcı Yayınları.

Gottiner, M. (2005). Postmodern göstergeler (Çev: E. Cengiz ve H. Gür). İstanbul: İmge Yayınları.

Greimas, A.J. (1987). Qn meaning selected writings in semiotic theory. Minneapolis, Canada: University of Minnesota Press.

Güngör, T. (2018). 1980 Sonrası Türk resim sanatunda figüratif eğilimler ve Mebmet Başbuğg (Sanatta Yeterlilik Tezi). Akdeniz Üniversitesi, Güzel Sanatlar Enstitüsü, Antalya.

Güngör, T . (2020). Çağdaş türk resim sanatında göç olgusu: Mehmet Başbuğ özelinde bakmak. Manas Sosyal Arastirmalar Dergisi , 9(3) , 1608-1626.

(Https://Karizmahaber.Com/Guncel/Prof-Dr-Mehmet-Basbug-Hayatini-Kaybetti/ 30.09.2020).

(Https://Www.Anatoliamuzayede.Com/Urun/769434/Mehmet-Basbug-Keciler-Tuval-Uzeri-Yagli-Boya-2005İmzali-60x80-Cm 30.09.2020).

(Https://Www.Artsurem.Com/Art/Artwork/Mehmet-Basbug/25/ 30.09.2020).

https://www.instagram.com/p/BIre5Tqhig// (24.01.2021).

Karaoğlu, A. (2000). Mehmet Başbuğ’un sanatı üzerine. Mehmet Başbuğ Kataloğu. İstanbul: Emlakbank.

Keten, H. (2018). Modern Sanatın Nesnesi Olarak Hayvan. Mehmet Akif Ersoy Üniversitesi Sosyal Bilimler Enstitiisü Dergisi, 8(15), 285-300.

Kıran, Z. ve Kıran, A. (2013). Dilbilime giriș. Ankara: Seçkin Yayınları.

Mehmet Basbuğ Sergi Katoloğu (2000). İstanbul: Emlak Sanat Galerisi.

Rifat, M. (2013). Açıklamall göstergebilim sǫ̈liügüi İstanbul: Türkiye İş Bankası Yayınları.

Soylu, R. (2018). Göstergebilim sanateseri çözümleme şemaları. Gǚel Sanatlarda Örnek Araștrmalar El Kitabı (Edt: Pelin Karabaş). İstanbul: Nobel Yayıncilık.

Tepecik, A. (2017). Anadolu'dan Tanrı Dağları'na, insanların ve atların ustass: Prof. Dr. Mehmet Başbuğ. Türk Yurdu Dergisi, 360, 70-75.

Topsakal, Ü ve İ. (2019). Fenomenolojik bir çalışma: Türk kültüründeki kurt kültü üzerine öğrenci düşünceleri. Bilig Dergisi, 89, 77-94.

Uçan, H. (2003). Edebiyat bilimi ve eleş̧tiri. İstanbul: Hece Yayınları.

\section{EXTENDED ABSTRACT}

Mehmet Başbuğ is an important artistic personality that has left his mark in contemporary Turkish painting art both with his paintings and with his educator identity. It is possible to see mostly Anatolian and Central Asian Turkish culture images in his paintings. Mehmet Başbuğ, who studied art at Gazi University Gazi Faculty of Education, Department of Art and Business Teaching, has also raised hundreds of students during the years he worked as a lecturer. Central Asia as well as in works of art in the Turkish government, Turkey has made both educational activities. He worked as an art educator and manager in Kyrgyzstan Manas University. He closely examined common symbols of Turkish culture with his observations in Central Asia and reflected important images of Turkish mythology in his paintings.

In this study, the animal images in the paintings of our teacher Mehmet Başbug and bearing important meanings in Turkish culture were examined with semiotic methods and it was tried to be analyzed with semiotics art work analysis schemes. Semiotics as an advanced science in the early twentieth century examines signs. The sign is something that indicates and refers to something other than itself. In addition to the signs and symptoms that people develop consciously, natural symptoms are also indicators. In addition, icons that are the images of objects and figures and symbols developed as a common language 
among people are other types of signs. The languages, alphabets, flags, national anthems and religious symbols, which are the national symbols of each nation, are their most important indicators.

According to Saussure, who is accepted as the founder of semiotics, semiotics consists of a signifier and a signified. Peirce adds an interpretative factor to this. Each sign contains connotations and deep meanings as well as its plain meaning. When a work of art is examined with the method of semiotics, the signs on the work are tried to be analyzed with a semantic analysis scheme, opposing meanings scheme, Gremias actors scheme and semiotic quadrilateral scheme. With the indicators on a work of art, it primarily shows the talent and artistic power of its artist. It also reflects the artistic understanding and possibilities of the period in which it was built. In addition, the images and symbolic expressions seen on the work of art refer to the meanings of national and universal culture.

Mehmet Başbuğ, who was born in the middle of the twentieth century and sadly passed away in the most productive period of his life, presents sections from the daily life of Anatolian and Central Asian Turkish people in his paintings. In particular, his works on the War of Independence refer to our national and moral values. Images and symbols of Turkish culture and mythology are very common in his paintings. His realistic and expressive figures sit on a strong pattern and composition. Its vivid and bright colors can also be considered as symbolic expressions and strong indicators of Turkish culture.

In Mehmet Başbuğ's paintings, some animals such as wolf, horse, donkey, deer, ox, cow, eagle, sheep, goat are special living figures, as well as making references to common codes of Anatolian and Central Asian Turkish culture, which can be regarded as important indicators.

Especially when the horse figure is considered as an indicator, it refers to the close friendship of people as well as national feelings and concepts such as courage, bravery, loyalty, freedom and independence. Although the donkey is also a mount, it refers to meanings such as diligence, work force, endurance, patience and stubbornness as an indicator. Sheep and goats have a very important place in Turkish culture, especially in nomadic communities starting from Central Asia until they reach Anatolia. When considered as an indicator, sheep refers to both abundance, fertility and obedience. In addition to abundance, abundance and sustenance in the goat, it can be considered as an indicator of resistance and resistance with its stubbornness. As an indicator, the wolf is the animal with the most deep mythological meanings in Turkish culture. It has almost become a symbol of Turkishness. It also means connotations such as courage, valor and friendship. Eagle is also an indicator that has symbolic meanings in Turkish culture. Especially, it stands out in Turkish art from double-headed eagle flags to Turkish motifs. The eagle is a sign of both freedom and domination. Ox, cow and bull are animals attributed to holiness, especially in ancient Egyptian and Indian societies. In Mehmet Başbuğ's paintings, the cow or ox becomes an indicator of obedience and fertility by referring to Anatolian folk culture. Deer are mostly included in Central Asian culture. It is the most powerful indicator of Mehmet Başbuğ's impressions in Central Asia.

As a result, Mehmet Başbuğ is an artist who has gained an important place in contemporary Turkish art with his images and symbols referring to the roots and common codes of Turkish culture. His paintings are more than just a description or a study of nature, they carry connotations and signs with deep meanings. The subjects he deals with and the figures he deals with refer to the awareness of Turkishness. Both the paintings he made and the students he raised with his strong educational personality are his greatest works. 